\title{
Modelling drug-related morbidity in Sweden using an expert panel of physicians
}

Katja M Hakkarainen, Daniel Alström, Staffan Hägg, Anders Carlsten and Hanna Gyllensten

\section{Linköping University Post Print}

N.B.: When citing this work, cite the original article.

The original publication is available at www.springerlink.com:

Katja M Hakkarainen, Daniel Alström, Staffan Hägg, Anders Carlsten and Hanna Gyllensten, Modelling drug-related morbidity in Sweden using an expert panel of physicians, 2012, European Journal of Clinical Pharmacology, (68), 9, 1309-1319.

http://dx.doi.org/10.1007/s00228-012-1244-3

Copyright: Springer Verlag (Germany)

http://www.springerlink.com/?MUD=MP

Postprint available at: Linköping University Electronic Press

http://urn.kb.se/resolve?urn=urn:nbn:se:liu:diva-76037 
Re-submitted to the European Journal of Clinical Pharmacology $30^{\text {th }}$ January 2012

\section{Authors}

Katja M Hakkarainen ${ }^{1}$

Daniel Alström ${ }^{1}$

Staffan Hägg 1,2,3

Anders Carlsten ${ }^{1,4}$

Hanna Gyllensten ${ }^{1}$

Title

\section{MODELLING DRUG-RELATED MORBIDITY IN SWEDEN USING} AN EXPERT PANEL OF PHYSICIANS

\section{Authors' affiliations and addresses}

${ }^{1}$ Nordic School of Public Health NHV, Box 12133, 40242 Gothenburg, Sweden

${ }^{2}$ Department of Drug Research/Clinical Pharmacology, Faculty of Health Sciences, Linköping University, 58183 Linköping, Sweden

${ }^{3}$ Department of Clinical Pharmacology, County Council of Östergötland, 58191 Linköping, Sweden

${ }^{4}$ Medical Products Agency, Box 26, 75103 Uppsala, Sweden

\section{Corresponding author}

Katja Hakkarainen

E-mail: katja.hakkarainen@nhv.se

Phone: +46(0)738427442

Fax No: +46(0)31691777 


\begin{abstract}
Purpose: In modelling studies using pharmacists' opinion, drug-related morbidity (DRM) and preventable DRM have been more common than in observational studies and the resulting costs are extensive. Modelling studies' estimates may vary depending on informants' profession. The purpose of this modelling study was to estimate the proportion of patients with DRM and preventable DRM and the cost-of-illness (COI) of DRM in Sweden based on physicians' expert opinion.
\end{abstract}

Method: A conceptual model of DRM was modified from previous studies. Using a modified Delphi technique, a panel of physicians $(n=19)$ estimated the probabilities of DRM, preventable DRM and clinical outcomes of DRM, separately for outpatients and inpatients. DRM included new medical problems (adverse drug reactions, drug dependence and intoxications by overdose) and therapeutic failure (insufficient effects of medicines and morbidity due to untreated indication). A COI analysis included the direct costs of DRM.

Results: Physicians estimated that $51 \pm 22 \%($ mean \pm SD) of outpatients experience DRM and $12 \pm 8 \%$ preventable DRM. Of inpatients, $54 \pm 17 \%$ was estimated to experience DRM and $16 \pm 7 \%$ preventable DRM. Of outpatients with DRM, $23 \pm 11 \%$ was estimated to experience preventable DRM, while this proportion for inpatients was $30 \pm 15 \%$. The estimated COI was EUR 376 per outpatient and EUR 838 per inpatient.

\title{
Conclusions:
}

Swedish physicians estimated that every other outpatient and inpatient experiences DRM, which is often preventable and costly. As physicians' estimates on the proportion of patients with DRM were higher than in observational studies in restricted sub-populations, DRM may be more common in the general population than observational studies suggest. 


\section{KEYWORDS}

Drug-related morbidity

Cost of illness

Preventability

Decision trees

Pharmacoepidemiology 


\section{BACKGROUND}

A significant proportion of patients is reported to suffer from drug-related morbidity (DRM), such as adverse drug reactions (ADRs) and therapeutic failure [1,2], but evidence from observational studies and modelling studies are partially inconsistent. In an American modelling study using probability estimates of an expert panel of pharmacists in the 1995, $40 \%$ of ambulatory patients receiving medication was estimated to experience DRM [3]. According to Swedish pharmacists' recent estimation, $61 \%$ of all patients utilising healthcare experience DRM [4]. These estimates on the proportion of patients with DRM are higher than in most observational studies, in which the median frequency of adverse drug events (ADEs) among inpatients is reported to be 6\% [2], and 5\% of hospital admission is estimated to be drug-related, with a range from $0.01 \%$ to $54 \%$ in individual studies [1]. In the modelling studies with a pharmacist expert panel, pharmacists' perception on DRM may be subjective and estimates on DRM could differ, if other health professionals were used as experts, as suggested by a modelling study in nursing homes [5].

In modelling studies with a pharmacist-panel, the costs to healthcare due to DRM are extensive, in Sweden EUR 6.6 billion among all patients in 2010 [4], and in the United States USD 89 billion among ambulatory patients in 1995 [3] and USD 117 billion in 2001 [6]. However, patient-level costs were EUR 1645 per patient with DRM in the Swedish modelling study [4], which is lower than in most observational studies [7]. As modelling studies' cost estimates are based on pharmacists' perceptions on the clinical outcomes of DRM, in addition to their high estimates on the proportion of patients with DRM, the costs of DRM may also differ if a panel of other health professionals was used in modelling studies.

For preventing unnecessary patient harm and costs for healthcare, the preventability of DRM is particularly interesting. The Swedish modelling study's estimate that $45 \%$ of all patients with DRM suffer from preventable DRM [4] was similar to or slightly higher than in observational studies [2,8-13]. However, the Swedish modelling study's conclusion [4] that $27 \%$ of all patients experienced preventable DRM was significantly higher than in observational studies $[10,11,13]$. 
Modelling studies using experts' opinion for probabilities of DRM and related outcomes may provide valuable evidence on DRM in a population level, as observational studies are limited to specific sub-population, such as patients of certain care units. However, the results of previous modelling studies using pharmacists' probability estimates, based on their subjective view and experience in clinical practice, are partially inconsistent with other evidence. Thus, other health professionals' estimates should be used in modelling studies to investigate whether results vary. The purpose of this modelling study was to estimate the proportion of patients with DRM and preventable DRM and to estimate the cost-of-illness (COI) of DRM in Sweden based on physicians' expert opinion. 


\section{METHODS}

A conceptual model on DRM with a decision tree was modified from a previous American study [3]. The model was modified for the Swedish health system and for an expert panel of physicians (Fig. 1). The panel estimated probabilities of DRM and related outcomes in the decision tree, using modified Delphi methodology with two rounds [14]. Physicians working in outpatient care $(n=11)$ provided estimates for outpatients, and physicians working with inpatients $(\mathrm{n}=8)$ for inpatients. However, DRM among inpatients could also originate from outpatient settings. To gain approximately 20 panellists representing both outpatient and inpatient care and different specialties, a strategic stratified sample of 20 physicians active in Drug and Therapeutics Committees was invited to participate in the study. Six strata represented specialties or combinations of specialties, and the desired number of participants in each stratum was chosen in proportion of patient consultations in each stratum. The invited physicians were also chosen to represent rural and urban as well as academic and nonacademic healthcare. When an invited physician in a stratum declined participation, another physician in the stratum was invited to replace the physician, based on a pre-defined list of potential participants representing different specialties. From a total of 53 invited physicians, 19 specialist physicians representing the six strata consented, forming the expert panel. Five were specialised in general medicine, four in internal medicine, and three in geriatrics. Each of the remaining seven was specialised either in psychiatry, dermatology, rheumatology, urology, infections diseases, general surgery or paediatrics. Six of the physicians practiced in university hospitals and eight in general hospitals. Eight of the physicians based in a hospital practiced primarily with inpatients and six with outpatients. Five physicians practiced in primary care in district healthcare centres. Twelve physicians were male and seven female, with a mean age of 57 years (range 45-69).

In section $\mathrm{A}$ of the decision tree, physicians estimated the probabilities of outcomes of drug therapy among their patients (Fig. 1). New medical problems (NMPs), therapeutic failure (TF) and a combination of NMPs and TF as outcomes represented DRM. DRM could originate from prescribed drugs, non-prescribed drugs or complementary medicines, but morbidity related to drugs without approval for medical purposes was excluded. NMPs included ADRs, drug dependence and intoxications by overdose. TF included insufficient effects of medicines due to erroneous therapy, including morbidity due to lack of drug therapy despite indication, 
or when rational use of medicines was insufficient. In section $\mathrm{B}$, physicians estimated the proportion of patients with preventable DRM according to established criteria, including DRM that was "due to a drug treatment procedure inconsistent with present day knowledge of good medical practice or was clearly unrealistic, taking the known circumstances into account" or DRM when "the prescription was not erroneous, but the drug event could have been avoided by an effort exceeding the obligatory demands" [15]. The clinical outcomes of DRM were estimated in section $\mathrm{C}$. In sections $\mathrm{A}$ and $\mathrm{C}$, the response alternatives were mutually exclusive. In section $\mathrm{C}$, respondents were instructed to choose the worst response alternative when multiple clinical outcomes due to DRM were present. The conceptual model was the same for outpatients and inpatients apart from one response alternative in section $\mathrm{C}$ (Fig. 1), where the probability of a hospitalisation was estimated for outpatients and the probability of prolonged hospital stay for inpatients. The Swedish conceptual model was piloted with six pharmacists, six physicians and four nurses, representing both outpatient and inpatient care. Based on the pilots, the arms of the decision tree were adapted for a panel of outpatient and inpatient physicians (Fig. 1) and the face and content validity of the final model was assessed.

In the first round, at least one researcher (DA, HG or $\mathrm{KH}$ ) instructed the physicians face-toface in interpreting the decision tree. The physicians provided their estimates independently, in writing, and were encouraged to leave written comments. Additional information was collected on the participants' age, sex and workplace. The participants also completed an appraisal of the decision tree, in which they estimated in a five-point Likert scale how easy each section of the decision tree was to answer. In the second round, conducted through mail, participants could adjust their estimates after receiving interquartile ranges of the entire panel's estimates and a copy of their own estimates from the first round. The appraisal of the decision tree could also be revised. As one physician made no revisions in section A, four in section $\mathrm{B}$, one in section $\mathrm{C}$, and five in the appraisal, answers from the first round were used for these questions. Answers were returned in a pre-paid envelope.

\section{Analyses}

\section{Proportion of patients with DRM and preventable DRM}


The estimates were analysed separately for outpatients and inpatients. The proportion of patients with DRM was calculated using mean probabilities for patients experiencing NMPs and TF.

The proportion of preventable DRM (NMPs or TF) among patients with DRM was calculated by taking respondents' mean estimates. The total proportion of patients with preventable DRM among patients with DRM was calculated by weighting, for each respondent, the proportion of patients with preventable NMPs and TF (among patients with NMPs and TF) by the mean proportion of NMP and TF patients among all DRM patients (i.e. patients with any NMPs or TF). The weighted estimates were summed for each respondent and a mean was taken.

The proportion of patients with preventable NMPs and TF among all patients was calculated by weighting, for each respondent, the proportion of patients with preventable NMPs and TF (among patients with DRM) by the estimated probabilities of NMPs and TF among all patients. The mean of the sum of these estimates represented the total proportion of patients with preventable DRM.

Even though the types of distributions of the responses were not apparent due to the small sample size, the distributions were reasonably symmetrical. Therefore and because means and medians did not differ notably, the use of means was considered appropriate. Calculations were done using STATA version 10.0.

\section{Cost-of-illness analyses}

The COI analysis was conducted separately for DRM among outpatients and inpatients, folding back in the decision tree (TreeAge Pro Excel 2009). Firstly, conditional probabilities for clinical outcomes were calculated by multiplying mean probabilities for each type of DRM with mean probabilities for clinical outcomes of each type of DRM. Secondly, each conditional probability was multiplied by its pathway costs (Table 1), resulting in cost estimates for each clinical outcome. The sum of these clinical outcome costs represented the total COI of DRM, per outpatient and inpatient. The annual COI of DRM among outpatients and inpatients was calculated under the assumption that $70 \%$ of residents in Sweden visit outpatient care and $9.5 \%$ of residents are hospitalised, at least once annually $[16,17]$. 
The pathway costs used in the main analyses and the minimum and maximum pathway costs for each clinical outcome were determined from their cost-generating components (Table 1). The minimum pathway costs represented the most conservative cost estimate and the maximum pathway costs a reasonable worst-case scenario. The cost-generating components were decided based on published literature [8,18-21], and the researchers' conservative estimates. Monetary values for the components were determined from national statistics [2224] and personal communications with register holders [Gyllensten H. Personal communication] on costs of healthcare and drug utilisation. The cost-generating components and pathway costs were the same for outpatients and inpatients apart from no additional treatment, additional treatment and specialist referral. For outpatients, the costs of these clinical outcomes included an initial contact to primary care, while contact to primary care was omitted from costs for inpatients. Swedish crowns were converted to Euro (EUR) using the 2010 exchange rate [25].

\section{Sensitivity analyses of cost-of-illness}

To investigate the robustness of the COI analysis, the probabilities of DRM and its clinical outcomes were varied from the first to the third quartile of the participants' estimates. In another sensitivity analysis, clinical outcomes with most insecurity in the COI analysis were investigated through Tornado diagrams, in which the determined cost-generating components and pathway costs for each clinical outcome are varied from minimum to maximum costs (TreeAge Pro Excel 2009). 


\section{RESULTS}

\section{Proportion of patients with DRM and preventable DRM}

Physicians estimated that $51 \pm 22 \%$ (mean \pm standard deviation) of all outpatients and $54 \pm 17 \%$ of all inpatients experience DRM (Table 2). Among outpatients with DRM, 24 $\pm 11 \%$ was estimated to experience preventable DRM. Among inpatients with DRM, DRM was considered preventable for $31 \pm 15 \% .12 \pm 8 \%$ of all outpatients and $16 \pm 7 \%$ of all inpatients were estimated to experience preventable DRM. The proportions of patients with all and preventable NMPs, TF and their combinations are presented in Table 2.

\section{Cost-of-illness of DRM}

Physicians estimated that $26 \%$ of outpatients with NMPs, $14 \%$ with TF and $8 \%$ with the combination of both require no addition treatment due to DRM (Table 3). Of inpatients, 27\% with NMPs, $7 \%$ with $\mathrm{TF}$ and $7 \%$ with their combinations was estimated to require no additional treatment. For the remaining proportions of outpatients and inpatients with DRM, the DRM was estimated to result in additional treatment, specialist referral, prolonged hospital stay, hospitalisation, advanced specialist care or death. Based on the probability estimates for these clinical outcomes, the COI was EUR 376 per outpatient and EUR 838 per inpatient (Table 4). Of the COI per outpatient, hospitalisations and advanced specialist care due to DRM caused $75 \%$ (283 EUR) of the costs. Prolonged hospital stay and advanced specialist care due to DRM caused 81\% (678 EUR) of the costs among inpatients. The COI of DRM per outpatient and inpatient correspond to EUR 730 per outpatient with DRM and EUR 1542 per inpatient with DRM. When investigating the types of DRM, the COI of NMPs was EUR 751 per outpatient experiencing NMPs exclusively and EUR 1036 per inpatient experiencing NMPs exclusively. The COI of TF was EUR 600 per outpatient experiencing TF exclusively and EUR 1094 per inpatient experiencing TF exclusively. The COI of combinations of NMPs and TF was EUR 887 among outpatients experiencing both NMPs and $T F$ and EUR 3252 among inpatients experiencing both NMPs and TF. Extrapolated to the Swedish population, the total annual COI of DRM was EUR 2.5 billion for outpatients and EUR 0.8 billion for inpatients.

\section{Sensitivity analyses of cost-of-illness}


The COI of DRM per outpatient ranged from EUR 97 for the first quartile to EUR 447 for the third quartile probability estimates. The range was EUR 209-1177 for inpatients. Of the clinical outcomes of DRM among outpatients, the costs differed the most for hospitalisation (cost range EUR 63-257), when the first and third quartile probability estimates were used. Among inpatients, the cost difference was the largest for advanced specialist care (cost range EUR 87-677). According to the Tornado diagrams, the COI among outpatients was the most sensitive to changes in costs resulting from hospitalisations, with cost estimates of EUR 330 per outpatient using minimum and EUR 445 using maximum pathway costs (Fig. 2 and 3). The COI among inpatients was the most sensitive to costs resulting from prolonged hospital stay (cost range EUR 509-1037). 


\section{DISCUSSION}

In our modelling study, Swedish physicians perceived that approximately half of their patients experience DRM. The estimates were almost equal for outpatients and inpatients. Our estimates were lower than Swedish pharmacists' estimation that $61 \%$ of all patients attending health care experience DRM [4], but higher than American pharmacists' estimate in 1995 that $40 \%$ of outpatients who receive medicines suffer from DRM [3]. Comparing the Swedish studies, pharmacists working clinically may have estimated the proportion of DRM higher, if they encounter patients with DRM in their clinical practice, rather than average patients. Alternatively, pharmacists working in the community may encounter persons with DRM who do not visit outpatient physicians. Pharmacists may also provide high DRM estimates, perhaps unconsciously, to justify their professional role. Physicians may have given lower estimates because they were asked to provide estimates from their own experience and may have perceived that acknowledging DRM would reflect poorly on their own practice. Nonetheless, the modelling studies combined suggest that up to $40-60 \%$ of all patients may experience DRM, even though results from modelling studies must be compared and interpreted with caution.

In our and previous modelling studies using health professionals' expert opinion [3,4], the proportion of patients with DRM is significantly higher than in reviews of observational studies [1,2], in which approximately 5-6\% of patients attending hospitals is estimated to experience DRM. As observational studies among outpatients commonly investigate drugrelated hospital admissions, estimates based on experts' opinions may be higher because they include DRM in primary care that does not lead to hospitalisations. For both inpatients and outpatients, part of DRM may be overseen in observational studies, because different data sources, such as self-reports and medical records, detect different types of DRM and none of them alone detects all DRM [26]. In addition, modelling studies' estimates may be higher due to a broader definition for DRM. TF is often unspecified in observational studies, potentially leading to overlooking it. When patients with TF exclusively are excluded from our results, physicians' estimates were $36 \%$ of outpatients and $34 \%$ of inpatients, still significantly higher than in observational studies. Finally, estimates on DRM in modelling studies using an expert panel may be high, because informants were active in Drug and Therapeutics Committees, and thus had an interest in drug safety. However, as physicians' estimates on DRM were also 
higher than in observational studies, high estimates based on pharmacists' expert opinion are not entirely explained by pharmacists' subjective view. Thus, DRM in the entire healthcare may be more common than observational studies suggest.

Based on Swedish physicians' estimates, the direct costs of DRM were EUR 376 per outpatient and EUR 838 per inpatient attending healthcare. Although differing methods for modelling DRM in different health systems hinders the direct comparison of the resulting costs, our estimate for outpatients is similar to American pharmacists' estimates that in the United States DRM cost USD 194 per physician outpatient visit in 1995 [3], and 376 USD in 2001 [6]. Our cost estimate for outpatients is also similar to cost estimates in Germany, where DRM was estimated to cost EUR 434 per outpatient visit, combining American probability estimates and German data on clinical outcomes [27]. However, Swedish pharmacists estimated DRM to cost markedly more, EUR 997 per patient attending healthcare [4]. The difference between Swedish pharmacists' and physicians' cost estimations is partially attributable to physicians' lower estimates for the proportion of patients with DRM. Moreover, the pharmacists' estimates were based on all patients attending healthcare, while physicians responded based on patients either in outpatient or inpatient settings. Thus, physicians' estimates did not represent DRM in all patients attending healthcare. For outpatients, the difference is largely explained by physicians' more conservative probability estimates for the most severe and expensive clinical outcomes. According to physicians, DRM leads to a hospitalisation among 5\% of outpatients with DRM, to advanced specialist care among $0-2 \%$ and to death among 0\%. According to pharmacists, DRM causes a hospitalisation to $9-15 \%$ of all patients with DRM, advanced specialist care to $2-4 \%$ and death to $1-4 \%$ [4]. As for the probability of DRM, the estimate differences may arise from different professional roles. Due to physicians' lower cost estimates per patient, the extrapolated annual costs of the DRM for Swedish healthcare, EUR 2.5 billion for outpatients and EUR 0.8 billion for inpatients, are also lower than estimated by pharmacists [4], EUR 6.6 billion in total for all patients. Even though physicians' costs estimates were lower than pharmacists', the annual costs of DRM for the Swedish healthcare were also substantial according to physicians.

Compared to observational studies' results [7], our cost estimates per patient with DRM are low, as in other modelling studies [4,27]. In observational studies, the cost of DRM has been USD 422-7062 per outpatient with DRM and USD 2284-5640 per inpatient with DRM (2000 
values) [7]. Based on physicians' estimates in our study, DRM costs EUR 730 per outpatient with DRM and EUR 1542 per inpatient with DRM, while Swedish pharmacists estimated that DRM costs EUR 1645 per patient with DRM [4]. In Germany, the average cost per outpatient with DRM was EUR 381 [27]. For both outpatients and inpatients, observational studies' average per patient costs were probably higher because they commonly focus on costs of emergency visits, hospitalisations and prolonged hospital stay. In modelling studies, the costs included also relatively inexpensive clinical outcomes, such as no additional treatment and additional treatment, which decreases the average costs.

Swedish physicians' estimates on the proportion of patients with preventable DRM were lower than estimates by pharmacists [4,28]. Among patients with DRM, 24\% of outpatients and $31 \%$ of inpatients were perceived to experience preventable DRM by the physicians, while Swedish pharmacists estimated that among patients with DRM, 45\% suffer from preventable DRM [4]. Although the proportion of preventable DRM was not assessed in the American modelling study, American pharmacists estimated that 53-60\% of NMPs and TF could be avoided if ambulatory patients received pharmaceutical care [28]. Pharmacists' avoidability estimates were higher than physicians' also in another American modelling study on DRM in nursing homes [5], in which pharmacists estimated that $48 \%$ and physicians that $34 \%$ of DRM is avoided through pharmaceutical care, although no statistical significance between the professionals' estimates was observed. In literature reviews of observational studies, the median or pooled preventability of drug-related admissions, ADEs or ADRs has been between $21 \%$ and $59 \%$, with a range of $11-90 \%$ in individual studies [2,8-13]. Pharmacists' preventability estimates were slightly higher and physicians' slightly lower than in most observational studies. The reasons for pharmacists' high and physicians' low estimates may be the same as for the occurrence of DRM. Preventability was also defined through the presence of sub-standard care in our study [15], which may have discouraged physicians to acknowledge preventability. As methods for assessing the preventability of DRM are limited and diverse [29,30], the preventability of DRM and the proportion of patients with preventable DRM remains unknown, but appears to range between 20-60\%.

Swedish physicians' estimates that $12 \%$ of all outpatients and $16 \%$ of all inpatients experience preventable DRM were lower than Swedish pharmacists' estimate, 27\% for all patients [4]. As discussed before, the difference is partially attributable to physicians' lower 
estimates for the proportion of patients with DRM, but mainly to physicians' lower preventability estimates. However, both expert panels' estimates are markedly higher than in observational studies, in which the median or pooled proportions of patients with preventable DRM have been between $2 \%$ and $4 \%[10,11,13]$. This difference originates from the expert panels' higher estimates on the proportion of all patients with DRM, while preventability estimates were similar. As for the proportion of patients with all DRM, these results suggest that also preventable DRM in the entire healthcare may be more common that observational studies have reported.

Several limitations arise from using a decision tree. The decision tree was a simplified model of DRM and thus, does not represent all scenarios for and outcomes of DRM. In our pilot study, informants perceived long-term consequences of DRM, such as residential care, impossible to estimate. We therefore excluded long-term consequences from the decision tree, which may have lead to underestimating the costs of DRM. As decision trees lack a time window [31], we were unable to determine the prevalence of DRM in a given time which limits the extrapolation of our results. Informants may also have considered lifetime prevalence, resulting in high estimates for patients experiencing DRM. However, we believe this is unlikely, because the physician were asked the proportion of patients that have various outcomes, opposite to have had which would refer to life time prevalence. In addition, we instructed our panellists to provide estimates based on their current experience.

As an expert panel and a modified Delphi technique were used for gaining probabilities in the decision tree, our estimates represent the physician panellists' perception and have to be interpreted with caution. Even though using empirical probability estimates in modelling studies is recommended, the Delphi technique is appropriate when no empirical data is available [32], which was the case for the proportion of patients with DRM and preventable and the clinical outcomes of DRM in the entire healthcare. Traditionally in the Delphi methodology, multiple rounds are performed until a consensus within the panel is reached. We decided in advance to conduct two rounds. Although mean estimates did not differ between the rounds, standard deviations narrowed slightly after the second round, though were still large. A better consensus may have been reached if further rounds had been performed. Further, the composition of the panel may have influenced the results, including the physicians' medical specialties, practice settings and previous experience. 
As definitions for DRM and criteria for preventability are diverse [30,33,34], our estimates may not be comparable to studies using other definitions and criteria. Unlike in the American modelling study [3], DRM could in our study originate from non-prescribed drugs or complementary medicines and TF could be caused by lack of drug therapy despite indication. Thus, we included DRM among all patients attending outpatient or inpatient care, rather than the number of visits resulting in prescribed drugs. Our informants may also have interpreted the definitions differently, causing variation in their estimates. To facilitate an accurate interpretation of the decision tree and the definitions, we purposefully selected physicians active in Drug and Therapeutics Committees. Further, we explained the decision tree and the definitions to each physician face-to-face before they provided probability estimates. Despite our efforts to facilitate the interpretation of the model, nine (47\%) physicians perceived section A, $12(63 \%)$ section $\mathrm{B}$ and $13(68 \%)$ section $\mathrm{C}$ of the decision tree as somewhat difficult or difficult (score 4 or 5 in a five-point Likert scale) to answer after the second round, which must be considered when their mean estimates are interpreted.

The COI of DRM was sensitive to changes in physicians' probability estimates for the proportion of patients with DMR and clinical outcomes of DRM, with almost five-fold cost increase from the most conservative probabilities to the least conservative. In addition, the COI analysis was sensitive to changes in the pre-determined pathway costs for clinical outcomes, with variations in pathway costs of hospitalisation and prolonged hospital stay influencing the COI analyses the most. Thus, the COI of DRM among outpatients and inpatients in our study are approximates and need to be verified in empirical studies. Since indirect costs were excluded, our cost estimations may be underestimations of the economic burden of DRM to the society.

\section{CONCLUSIONS}

Swedish physicians estimated that every other outpatient and inpatient experiences DRM, which is often preventable and costly. These estimates were lower than Swedish pharmacists', indicating that informants' profession influences the results in modelling studies using experts' estimates. Physicians' estimates on the proportion of patients with DRM in the entire healthcare were still higher than in observational studies in restricted sub-populations. Thus, 
both non-preventable and preventable DRM may be more common in the general population than the current evidence suggests. To examine the findings of modelling studies, future empirical research should investigate DRM and its characteristics in the general population. 


\section{ACKNOWLEDGEMENTS}

We acknowledge Professor Lyle Bootman and colleagues in the College of Pharmacy, University of Arizona, for access to material on their conceptual model. We also thank the physician panellists and the participants in the pilot. The current study was conducted as part of the project Drug-Related Morbidity in Sweden (DRUMS). The authors thank Karolina Andersson Sundell, Anna K Jönsson and Clas Rehnberg in the DRUMS research group for their contribution to designing the current study. The study was funded by an unrestricted grant from The National Corporation of Swedish Pharmacies (Apoteket AB).

\section{CONFLICTS OF INTEREST}

The authors' work was independent of the sponsor, The National Corporation of Swedish Pharmacies (Apoteket AB), who had no role in the study design, data collection, analysis and interpretation, writing the manuscript, or in the decision to submit the manuscript for publication. The authors declare that they have no conflicts of interest.

\section{DISCLAIMER}

The opinions or assertions contained herein are the private views of the authors and are not to be construed as official or as reflecting the views of the Medical Product Agency. 


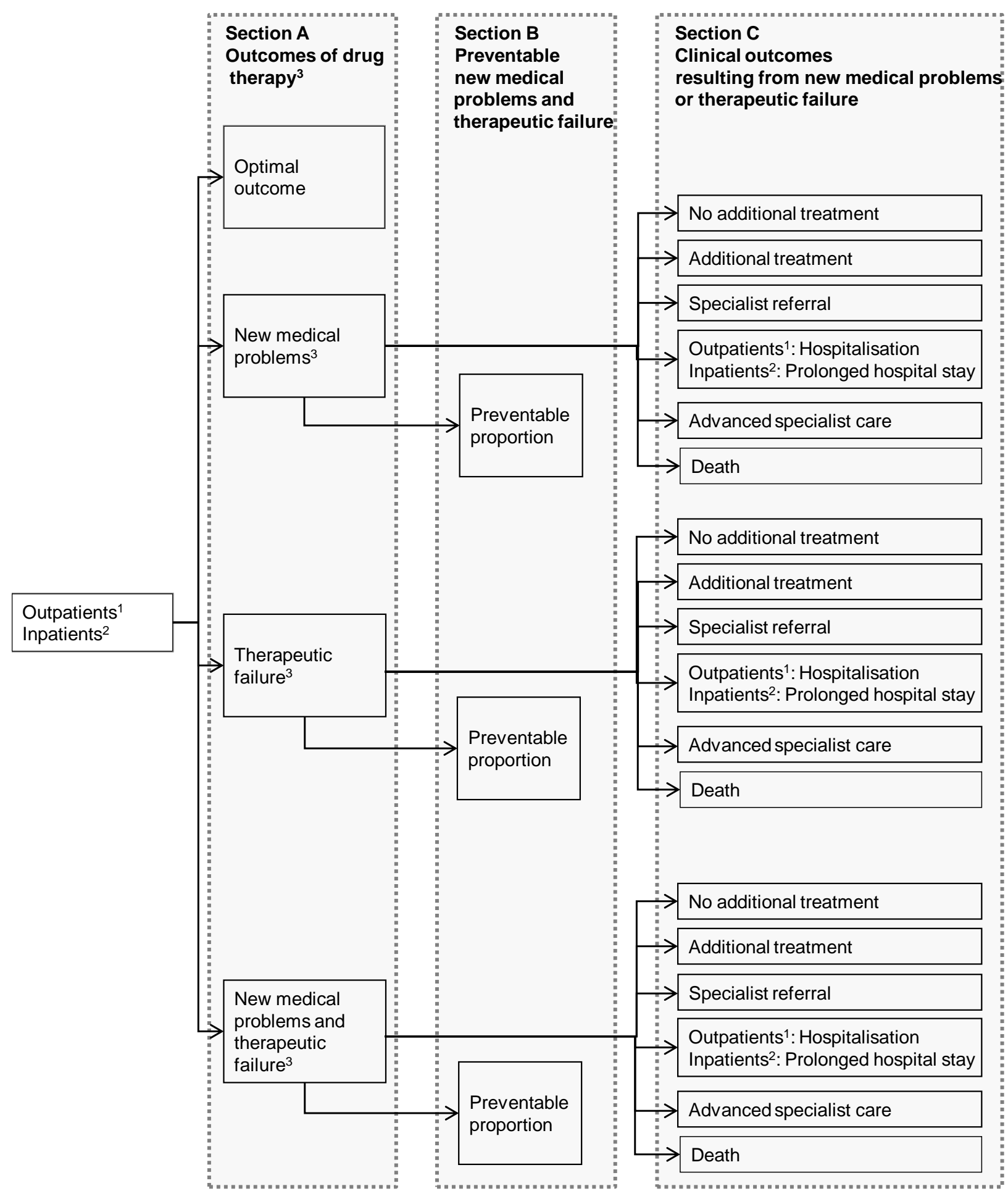

Fig. 1 Layout and response alternatives in the conceptual model on drug-related morbidity ${ }^{1}$ Physicians working in outpatient care $(\mathrm{n}=11)$ provided estimates for outpatients

${ }^{2}$ Physicians working with inpatients $(\mathrm{n}=8)$ provided estimates for inpatients

${ }^{3}$ Patients with new medical problem, therapeutic failure or their combinations represent patients with drugrelated morbidity 


\section{Clinical outcomes of DRM}

- $\min$ to max pathway costs (EUR)

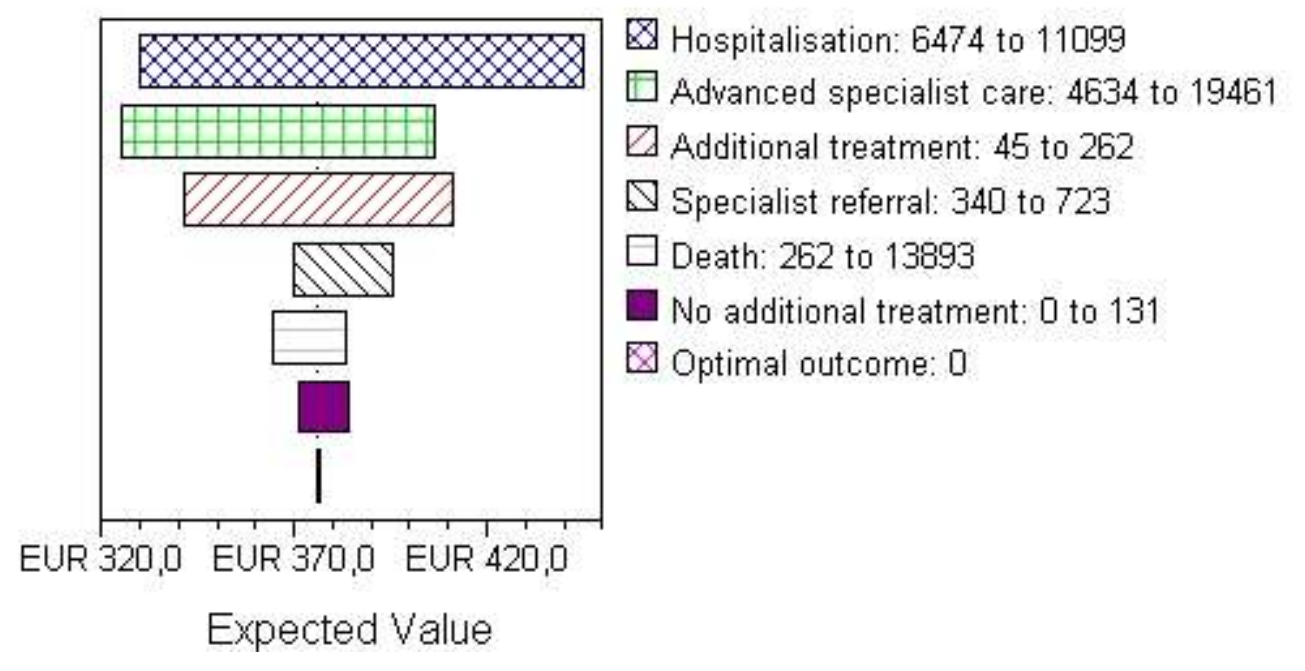

Fig. 2 Tornado diagram sensitivity analysis for the cost-of-illness of drug-related morbidity (DRM) among outpatients. The expected value in is the resulting costs from varying the pathway costs of each clinical outcome from minimum ( $\mathrm{min}$ ) to maximum (max) costs in euro (EUR) 


\section{Clinical outcomes of DRM}

\section{- min to max pathway costs (EUR)}

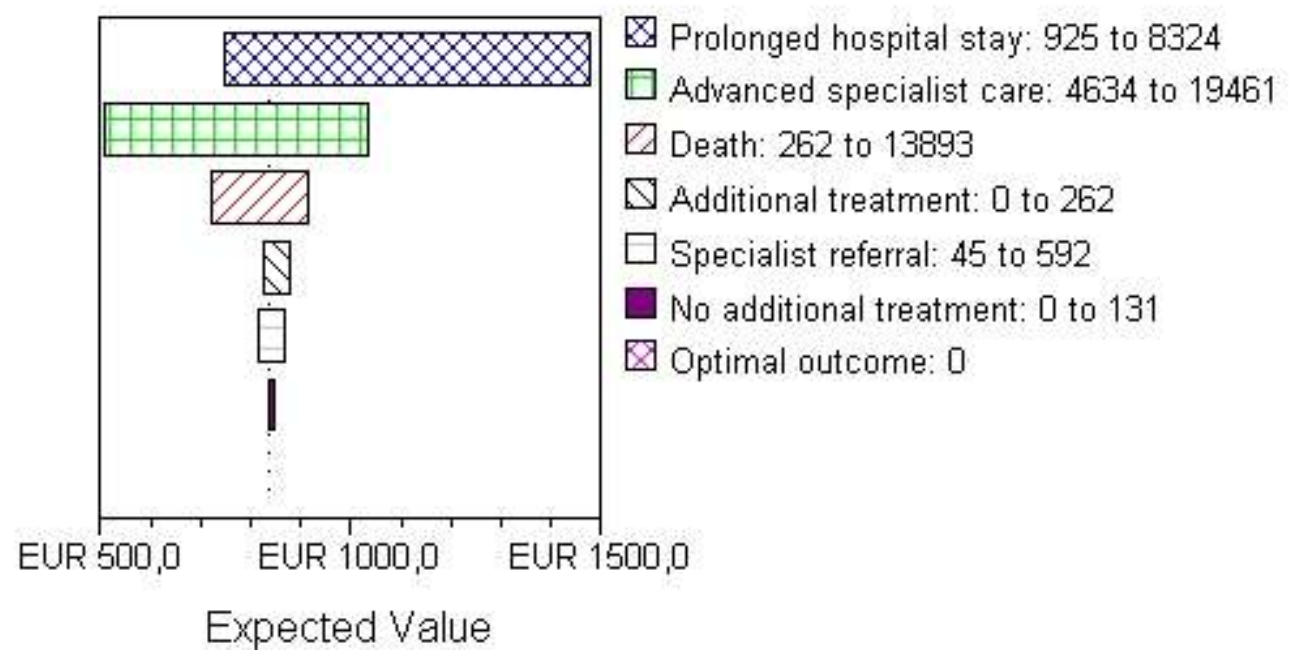

Fig. 3 Tornado diagram sensitivity analysis for the cost-of-illness of drug-related morbidity (DRM) among inpatients. The expected value in is the resulting costs from varying the pathway costs of each clinical outcome from minimum (min) to maximum (max) costs in euro (EUR) 
Table 1 Cost-generating components and pathway costs of clinical outcomes resulting from drug-related morbidity, used in the main analysis and the Tornado diagram sensitivity analysis

\begin{tabular}{|c|c|c|c|c|c|c|}
\hline \multirow{2}{*}{ Clinical outcome } & \multicolumn{2}{|l|}{ Main analysis } & \multicolumn{2}{|c|}{ Minimum estimation } & \multicolumn{2}{|c|}{ Maximum estimation } \\
\hline & $\begin{array}{l}\text { Cost-generating } \\
\text { components }\end{array}$ & $\begin{array}{l}\text { Pathway cost } \\
\text { (EUR) }\end{array}$ & $\begin{array}{l}\text { Cost-generating } \\
\text { components }\end{array}$ & $\begin{array}{l}\text { Pathway cost } \\
\text { (EUR) }\end{array}$ & $\begin{array}{l}\text { Cost-generating } \\
\text { components }\end{array}$ & $\begin{array}{l}\text { Pathway cost } \\
\text { (EUR) }\end{array}$ \\
\hline $\begin{array}{l}\text { No additional } \\
\text { treatment }\end{array}$ & $\begin{array}{c}\text { Outpatients: } 1 \text { telephone call to } \\
\text { physician }{ }^{\mathrm{a}} \\
\text { Inpatients: no additional } \\
\text { healthcare contact }\end{array}$ & $\begin{array}{l}\text { Outpatients: } 44 \\
\text { Inpatients: } 0\end{array}$ & $\begin{array}{l}\text { No additional healthcare } \\
\text { contact }\end{array}$ & 0 & 1 physician visit $^{\mathrm{a}}$ & 131 \\
\hline $\begin{array}{l}\text { Additional } \\
\text { treatment }\end{array}$ & $\begin{array}{l}\text { Outpatients: } 1 \text { physician visit }{ }^{\mathrm{a}} \\
+1 \text { additional prescribed drug } \\
\text { Inpatients: } 1 \text { nurse consultation } \\
+1 \text { additional prescribed } \text { drug }^{\mathrm{b}}\end{array}$ & $\begin{array}{l}\text { Outpatients: } 151 \\
\text { Inpatients: } 65\end{array}$ & $\begin{array}{l}\text { Outpatients: } 1 \text { nurse visit } \\
\text { Inpatients: No additional } \\
\text { healthcare contact }\end{array}$ & $\begin{array}{l}\text { Outpatients: } 45 \\
\text { Inpatients: } 0\end{array}$ & 2 physician visits $^{\mathrm{a}}$ & 262 \\
\hline Specialist referral & $\begin{array}{c}\text { Outpatients: } 1 \text { physician visit }{ }^{\mathrm{a}} \\
+1 \text { specialist physician visit } \\
\text { Inpatients: } 1 \text { specialist physician } \\
\text { consultation }^{\mathrm{a}}\end{array}$ & $\begin{array}{l}\text { Outpatients: } 427 \\
\text { Inpatients: } 296\end{array}$ & $\begin{array}{l}\text { Outpatients: } 1 \text { telephone call } \\
\text { to physician }{ }^{\mathrm{a}} \\
+1 \text { specialist physician visit }{ }^{\mathrm{a}} \\
\text { Inpatients: } 1 \text { nurse } \\
\text { consultation }^{\mathrm{a}}\end{array}$ & $\begin{array}{l}\text { Outpatients: } 340 \\
\text { Inpatients: } 45\end{array}$ & $\begin{array}{l}\text { Outpatients: } 1 \text { physician } \\
\text { visit }^{\mathrm{a}}+2 \text { specialist } \\
\text { physician visit }^{\mathrm{a}} \\
\text { Inpatients: } 2 \text { specialist } \\
\text { physician consultations }\end{array}$ & $\begin{array}{l}\text { Outpatients: } 723 \\
\text { Inpatients: } 592\end{array}$ \\
\hline $\begin{array}{l}\text { Prolonged hospital } \\
\text { stay }\end{array}$ & $\begin{array}{l}2 \text { additional days in hospital } \\
\qquad[18,19]^{\mathrm{c}}\end{array}$ & 1850 & 1 additional day in hospital $^{\mathrm{c}}$ & 925 & $\begin{array}{l}9 \text { additional days in } \\
\text { hospital }[20]^{\mathrm{c}}\end{array}$ & 8324 \\
\hline Hospitalisation & 9 days in hospital $[8]^{c}$ & 8324 & 7 days in hospital $[8]^{\mathrm{c}}$ & 6474 & 12 days in hospital $[8]^{c}$ & 11099 \\
\hline $\begin{array}{l}\text { Advanced } \\
\text { specialist care }\end{array}$ & 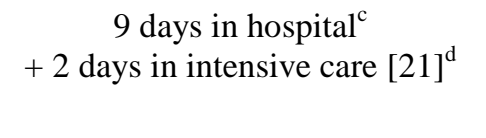 & 13893 & $\begin{array}{l}2 \text { days in hospital } \\
+1 \text { day in intensive care } \\
\text { d }\end{array}$ & 4634 & $\begin{array}{l}9 \text { days in hospital }^{c} \\
+4 \text { days in intensive }^{\text {care }^{d}}\end{array}$ & 19461 \\
\hline Death & 9 days in hospital $^{\mathrm{c}}$ & 8324 & 2 physician consultations ${ }^{\mathrm{a}}$ & 262 & $\begin{array}{l}9 \text { days in hospital } \\
+2 \text { days in intensive } \\
\text { care }^{\mathrm{d}}\end{array}$ & 13893 \\
\hline
\end{tabular}

\section{EUR Euro}

${ }^{a}$ Average cost of a physician (EUR 131), nurse (EUR 45) or specialist physician (EUR 296) consultation in somatic healthcare in Sweden during 2010, and telephone calls are weighted as one third of the cost of a visit [23]

${ }^{\mathrm{b}}$ Average benefit (EUR 20) of a dispensed prescription drug in Sweden during 2010 [Gyllensten H. Personal communication]

${ }^{c}$ Average daily hospital cost in somatic healthcare in Sweden during 2009 (EUR 909) [22], adjusted to 2010 value using a Swedish healthcare inflation index (price index with 
quality-adjusted wages for the county, including medicines $1.7 \%$ ) [24]

${ }^{\mathrm{d}}$ Average daily cost in an intensive care in Sweden during 2009 (EUR 2738), estimated using the assumption that personnel costs are 70\% of the total costs [Gyllensten H.

Personal communication], adjusted to 2010 value using a Swedish healthcare inflation index (price index with quality-adjusted wages for the county, including medicines $1.7 \%$ ) 
Table 2 Mean proportions of outpatients and inpatients with DRM and preventable DRM estimated by physicians $(n=19)$, by type of DRM

Type of DRM

\begin{tabular}{lcccc} 
& \multicolumn{2}{c}{$\%($ SD) } & \multicolumn{2}{c}{$\%$ (SD) } \\
\cline { 2 - 5 } New medical problem & Outpatients & Inpatients & Outpatients & Inpatients \\
Therapeutic failure & $16(15)$ & $22(10)$ & $21^{\mathrm{b}}(13)$ & $43^{\mathrm{b}}(13)$ \\
$\begin{array}{l}\text { New medical problem } \\
\text { therapeutic failure }\end{array}$ & $10(8)$ & $21(6)$ & $29^{\mathrm{c}}(19)$ & $29^{\mathrm{c}}(15)$ \\
TOTAL & $51^{\mathrm{a}}(22)$ & $54^{\mathrm{a}}(17)$ & $24^{\mathrm{e}}(11)$ & $25^{\mathrm{d}}(13)$ \\
\hline
\end{tabular}

$D R M$ drug-related morbidity

$S D$ standard deviation

${ }^{\mathrm{a}}$ Calculated by summing the proportions of DRM types. Because of rounding, the sum may not equal to the total \%

${ }^{\mathrm{b}}$ Among patients with new medical problems exclusively

${ }^{\mathrm{c}}$ Among patients with therapeutic failure exclusively

${ }^{\mathrm{d}}$ Among patients with a combination of new medical problems and therapeutic failure

${ }^{\mathrm{e}}$ Calculated by weighting the proportion of patients with preventable new medical problems and therapeutic failure (among patients with new medical problems and therapeutic failure) by the proportion of patients with new medical problems and therapeutic failure among all DRM patients
Proportion of patients with preventable DRM among patients with DRM $\%$ (SD)

Proportion of patients with DRM among all patients Inpatients

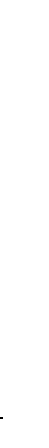


Table 3 Mean and conditional probabilities of clinical outcomes due to drug-related morbidity estimated by physicians $(\mathrm{n}=19)$, separately among outpatients and inpatients

\begin{tabular}{|c|c|c|c|c|}
\hline \multirow{2}{*}{$\begin{array}{l}\text { Clinical outcomes } \\
\text { of } \mathrm{DRM}^{\mathrm{a}}\end{array}$} & \multicolumn{2}{|c|}{ Mean probabilities } & \multicolumn{2}{|c|}{ Conditional probabilities $^{b}$} \\
\hline & $\begin{array}{c}\text { Outpatients } \\
\%\end{array}$ & $\begin{array}{c}\text { Inpatients } \\
\%\end{array}$ & $\begin{array}{c}\text { Outpatients } \\
\%\end{array}$ & $\begin{array}{c}\text { Inpatients } \\
\%\end{array}$ \\
\hline \multicolumn{5}{|l|}{ New medical problems ${ }^{\mathrm{a}}$} \\
\hline No additional treatment & 26 & 27 & 7 & 6 \\
\hline Additional treatment & 55 & 36 & 14 & 8 \\
\hline Specialist referral & 12 & 13 & 3 & 3 \\
\hline Prolonged hospital stay & - & 18 & - & 4 \\
\hline Hospitalisation & 5 & - & 1 & - \\
\hline Advanced specialist care & 1 & 3 & 0 & 1 \\
\hline Death & 0 & 3 & 0 & 1 \\
\hline \multicolumn{5}{|l|}{ Therapeutic failure $^{a}$} \\
\hline No additional treatment & 14 & 7 & 2 & 2 \\
\hline Additional treatment & 70 & 46 & 11 & 10 \\
\hline Specialist referral & 11 & 20 & 2 & 4 \\
\hline Prolonged hospital stay & - & 21 & - & 4 \\
\hline Hospitalisation & 5 & - & 1 & - \\
\hline Advanced specialist care & 0 & 3 & 0 & 1 \\
\hline Death & 0 & 2 & 0 & 0 \\
\hline \multicolumn{5}{|l|}{$\begin{array}{l}\text { New medical problems and } \\
\text { therapeutic failure }\end{array}$} \\
\hline No additional treatment & 8 & 7 & 1 & 1 \\
\hline Additional treatment & 68 & 35 & 7 & 4 \\
\hline Specialist referral & 17 & 23 & 2 & 3 \\
\hline Prolonged hospital stay & - & 13 & - & 2 \\
\hline Hospitalisation & 5 & - & 0 & - \\
\hline Advanced specialist care & 2 & 19 & 0 & 2 \\
\hline Death & 0 & 3 & 0 & 0 \\
\hline
\end{tabular}

$D R M$ drug-related morbidity

${ }^{\mathrm{a}} \mathrm{New}$ medical problems, therapeutic failure and their combinations represent drug-related morbidity

${ }^{\mathrm{b}}$ Conditional probability is the proportion of all patients experiencing a specific clinical outcome due to new medical problems or therapeutic failure, and is calculated by multiplying probabilities of new medical problems and therapeutic failure by the probabilities of their clinical outcomes 
Table 4 Cost-of-illness of drug-related morbidity per outpatient and inpatient, separately for each clinical outcome

\begin{tabular}{lcc}
\hline $\begin{array}{l}\text { Clinical outcomes } \\
\text { of DRM }\end{array}$ & $\begin{array}{c}\text { Cost-of-illness per } \\
\text { outpatient }\end{array}$ & $\begin{array}{c}\text { Cost-of-illness per } \\
\text { inpatient } \\
\end{array}$ \\
\hline
\end{tabular}

New medical problems ${ }^{a}$

No additional treatment

30

Additional treatment

$22 \quad 5$

Specialist referral

$14 \quad 8$

Prolonged hospital stay

$-\quad 74$

Hospitalisation

107

Advanced specialist care

$40 \quad 91$

Death

8

48

Therapeutic failure ${ }^{a}$

No additional treatment

Additional treatment

Specialist referral

$8 \quad 12$

Prolonged hospital stay 81

Hospitalisation

61

Advanced specialist care

8

86

Death

1

41

New medical problems and therapeutic failure ${ }^{a}$

No additional treatment

Additional treatment 0

Specialist referral

$10 \quad 3$

Prolonged hospital stay

78

Hospitalisation

$\begin{array}{ll}- & 28\end{array}$

Advanced specialist care 39

Death

28

318

\begin{tabular}{l} 
Total cost-of-illness $376^{\mathrm{b}}$ \\
\hline$D R M$ drug-related morbidity \\
EUR Euro \\
${ }^{\mathrm{a}}$ New medical problems, therapeutic failure and their combinations represent drug-related \\
morbidity \\
${ }^{\mathrm{b}}$ The same as by folding back of the decision tree, the total cost-of-illness may not total the \\
sum of the costs of clinical outcomes because of rounding
\end{tabular}




\section{REFERENCES}

1. Leendertse AJ, Visser D, Egberts AC, van den Bemt PM. The relationship between study characteristics and the prevalence of medication-related hospitalizations: a literature review and novel analysis. Drug Saf 2010;33(3):233-244

2. Krahenbuhl-Melcher A, Schlienger R, Lampert M, Haschke M, Drewe J, Krahenbuhl S. Drug-related problems in hospitals: a review of the recent literature. Drug Saf 2007;30(5):379-407

3. Johnson JA, Bootman JL. Drug-related morbidity and mortality. A cost-of-illness model. Arch Intern Med 1995;155(18):1949-1956

4. Gyllensten H, Hakkarainen KM, Jönsson AK, Andersson Sundell K, Hägg S, Rehnberg C, et al. Modelling drug-related morbidity in Sweden using an expert panel of pharmacists. Submitted 2011

5. Bootman JL, Harrison DL, Cox E. The health care cost of drug-related morbidity and mortality in nursing facilities. Arch Intern Med 1997;157(18):2089-2096

6. Ernst FR, Grizzle AJ. Drug-related morbidity and mortality: updating the cost-of-illness model. J Am Pharm Assoc 2001;41(2):192-199

7. Rodriguez-Monguio R, Otero MJ, Rovira J. Assessing the economic impact of adverse drug effects. Pharmacoeconomics 2003;21(9):623-650

8. Goettler M, Schneeweiss S, Hasford J. Adverse drug reaction monitoring--cost and benefit considerations. Part II: cost and preventability of adverse drug reactions leading to hospital admission. Pharmacoepidemiol Drug Saf 1997;6 Suppl. 3:S79-90

9. Beijer HJ, de Blaey CJ. Hospitalisations caused by adverse drug reactions (ADR): a metaanalysis of observational studies. Pharm World Sci 2002;24(2):46-54

10. Winterstein AG, Sauer BC, Hepler CD, Poole C. Preventable drug-related hospital admissions. Ann Pharmacother 2002;36(7-8):1238-1248 
11. Kanjanarat P, Winterstein AG, Johns TE, Hatton RC, Gonzalez-Rothi R, Segal R. Nature of preventable adverse drug events in hospitals: a literature review. Am J Health Syst Pharm 2003;60(17):1750-1759

12. Thomsen LA, Winterstein AG, Sondergaard B, Haugbolle LS, Melander A. Systematic review of the incidence and characteristics of preventable adverse drug events in ambulatory care. Ann Pharmacother 2007;41(9):1411-1426

13. Hakkarainen KM, Hedna K, Petzold M, Hägg S. Percentage of patients with preventable adverse drug reactions and the preventability of adverse drug reactions - A meta-analysis. Submitted 2011

14. Brown BB (1968) Delphi process: A methodology used for the elicitation of opinions of experts. RAND Corporation. http://www.rand.org/pubs/papers/P3925.html. Accessed 21 Oct 2011

15. Hallas J, Harvald B, Gram LF, Grodum E, Brosen K, Haghfelt T, et al. Drug related hospital admissions: the role of definitions and intensity of data collection, and the possibility of prevention. J Intern Med 1990;228(2):83-90

16. Nysam (2010) Key figures 2009 in healthcare - Report on consumption of healthcare [In Swedish]. http://mk.quicknet.se/220986/upload/bilder/0/v_rdkonsumtion_09_rapport.pdf. Accessed 28 Sep 2011

17. Statistics Sweden (2011) Population in Sweden according to gender and age on 31st December 2010 [in Swedish]. http://www.scb.se/Pages/TableAndChart_262459.aspx. Accessed 5 Nov 2011

18. Bates DW, Spell N, Cullen DJ, Burdick E, Laird N, Petersen LA, et al. The costs of adverse drug events in hospitalized patients. Adverse Drug Events Prevention Study Group. JAMA 1997;277(4):307-311

19. Evans RS, Classen DC, Stevens LE, Pestotnik SL, Gardner RM, Lloyd JF, et al. Using a hospital information system to assess the effects of adverse drug events. Proc Annu Symp Comput Appl Med Care 1993:161-165 
20. Moore N, Lecointre D, Noblet C, Mabille M. Frequency and cost of serious adverse drug reactions in a department of general medicine. Br J Clin Pharmacol 1998;45(3):301-308

21. Vargas E, Terleira A, Hernando F, Perez E, Cordon C, Moreno A, et al. Effect of adverse drug reactions on length of stay in surgical intensive care units. Crit Care Med 2003;31(3):694-698

22. Swedish Association of Local Authorities and Regions (2010) Comparison of costs and performance in hospital clinics in 2009 [In Swedish].

http://www.skl.se/vi_arbetar_med/statistik/publikationer_-statistik/tkb_2009. Accessed 20 Oct 2011

23. Swedish Association of Local Authorities and Regions (2011) Statistics on healthcare and regional development 2010 - Activities and economy in local authorities and regions [in Swedish]. http://brs.skl.se/brsbibl/kata_documents/doc40006_1.pdf. Accessed 28 Sep 2011

24. Swedish Association of Local Authorities and Regions (2011) Wage and price change in the county and consumer price index [In Swedish]. http://www.skl.se/vi_arbetar_med/ekonomi/budget_och_planering/prisindex/landstingspri sindex. Accessed 20 Oct 2011

25. Sveriges Riksbank (2011) Currency exchange rates - Annual average 2010 [in Swedish]. http://www.riksbank.se/templates/Page.aspx?id=15867. Accessed 28 Sep 2011

26. Morimoto T, Gandhi TK, Seger AC, Hsieh TC, Bates DW. Adverse drug events and medication errors: detection and classification methods. Qual Saf Health Care 2004;13(4):306-314

27. Stark RG, John J, Leidl R. Health care use and costs of adverse drug events emerging from outpatient treatment in Germany: a modelling approach. BMC Health Serv Res 2011;11:9

28. Johnson JA, Bootman JL. Drug-related morbidity and mortality and the economic impact of pharmaceutical care. Am J Health Syst Pharm 1997;54(5):554-558 
29. Ferner RE, Aronson JK. Preventability of drug-related harms - part I: a systematic review. Drug Saf 2010;33(11):985-994

30. Hakkarainen KM, Andersson Sundell K, Petzold M, Hägg S. Methods for assessing the preventability of adverse drug events - A systematic review. Drug Saf 2012;35(2):105126

31. Petrou S, Gray A. Economic evaluation using decision analytical modelling: design, conduct, analysis, and reporting. BMJ (Clin Research ed ) 2011;342:d1766

32. Simoens S. Using the Delphi technique in economic evaluation: time to revisit the oracle? J Clin Pharm Ther 2006;31(6):519-522

33. Aronson JK, Ferner RE. Clarification of terminology in drug safety. Drug Saf 2005;28(10):851-870

34. Aronson JK, Ferner RE. Preventability of drug-related harms - part II: proposed criteria, based on frameworks that classify adverse drug reactions. Drug Saf 2010;33(11):9951002 